\title{
Rainfall Determines Shallow Soil Seepage in a Piedmont Summer Pasture of Alpine Meadow on the Northeastern Qinghai-Tibetan Plateau
}

\author{
Hongqin $\mathrm{Li}^{1,+}$, Yongsheng Yang ${ }^{2,3,+}$, Fawei Zhang ${ }^{2,3,4, *} \mathbb{D}$, Xiaowei Guo ${ }^{3}$, Yikang $\mathrm{Li}^{3}, \mathrm{Li} \mathrm{Lin}^{3}$, Yingnian $\mathrm{Li}^{2,3}$, \\ Guangmin $\mathrm{Cao}^{3}$ and Huakun Zhou ${ }^{2,3,4}$ \\ 1 College of Life Sciences, Luoyang Normal University, Luoyang 471934, China; lihongqin_00@126.com \\ 2 Institute of Sanjiangyuan National Park, Chinese Academy of Sciences, Xining 810001, China; \\ yyssolider@126.com (Y.Y.); ynli@nwipb.cas.cn (Y.L.); hkzhou@nwipb.cas.cn (H.Z.) \\ 3 Key Laboratory of Adaptation and Evolution of Plateau Biota, Northwest Institute of Plateau Biology, \\ Chinese Academy of Sciences, Xining 810001, China; xwguo1206@163.com (X.G.); liyikang501@163.com (Y.L.); \\ hanxiao_2000_00@126.com (L.L.); caogm@nwipb.cas.cn (G.C.) \\ 4 Qinghai Provincial Key Laboratory of Restoration Ecology in Cold Region, Northwest Institute of Plateau \\ Biology, Chinese Academy of Sciences, Xining 810001, China \\ * Correspondence: mywing963@126.com \\ + These authors contribute equally.
}

Citation: Li, H.; Yang, Y.; Zhang, F.; Guo, X.; Li, Y.; Lin, L.; Li, Y.; Cao, G.; Zhou, H. Rainfall Determines Shallow Soil Seepage in a Piedmont Summer Pasture of Alpine Meadow on the Northeastern Qinghai-Tibetan Plateau. Water 2021, 13, 2815. https://doi.org/10.3390/w13202815

Academic Editor: Jiangfeng Wei

Received: 17 August 2021

Accepted: 7 October 2021

Published: 10 October 2021

Publisher's Note: MDPI stays neutral with regard to jurisdictional claims in published maps and institutional affiliations.

Copyright: (c) 2021 by the authors. Licensee MDPI, Basel, Switzerland. This article is an open access article distributed under the terms and conditions of the Creative Commons Attribution (CC BY) license (https:/ / creativecommons.org/licenses/by/ $4.0 /)$.

\begin{abstract}
Soil seepage is an important component used for quantifying hydrological processes that remains unclear in high-altitude alpine meadows. Shallow soil seepage was continuously measured using an auto-logged micro-lysimeter (diameter $=30 \mathrm{~cm}$, depth $=30 \mathrm{~cm}$ ) from July 2018 to June 2019 in a piedmont summer pasture of alpine meadow on the Northeastern Qinghai-Tibetan Plateau. The results showed that all the shallow soil seepage events occurred during the non-frozen period from April to September and that the cumulative amount was $106.8 \mathrm{~mm}$, representing about $1 / 5$ of the annual precipitation. The maximum and minimum monthly soil seepage were $30.7 \mathrm{~mm}$ in September and $1.0 \mathrm{~mm}$ in April, respectively. The boosted regression trees (BRT) model's area under the curve averaged 0.92 and revealed that the daily half-hour rainfall frequency, volumetric soil water content, and air temperature played significant roles in the daily soil seepage probability, with the cumulative relative contribution of $68 \%$. The stepwise linear regression analysis showed that the rainfall amount accounted for $59 \%$ of the variation in the daily amount of soil seepage. The monthly soil seepage was found to be significantly correlated with the monthly rainfall frequency $(r=0.86, p=0.005)$. Our results highlighted that rainfall, including its amount and frequency, was the key determinant of the probability and amount of shallow soil seepage in the piedmont summer pasture of alpine meadows. These findings will be helpful for improving predictions of the water budgets of piedmont alpine meadows.
\end{abstract}

Keywords: micro-lysimeter; soil seepage probability; soil seepage amount; boosted regression trees; piedmont summer pasture

\section{Introduction}

Soil seepage is a key element of terrestrial water budgets and plays an essential role in aquifer charges and river flows [1,2]. This is especially true for high-altitude alpine regions, which are generally referred to as "water towers" for the lowlands [3,4]. Due to the seasonal freeze-thaw cycle and the distinct stratification of organic matter content along with soil profile in alpine meadows [5,6], soil seepage will evidently be different from prior findings yet is a poorly understood part of hydrological processes [7]. However, previous studies on this topic have usually been based on model simulations [8,9]; few observational studies have been conducted in cold areas [10,11]. Therefore, quantifying the soil seepage and its underlying environmental controls would further improve our 
knowledge of the ecohydrological processes in alpine regions and enhance our ability to estimate water resources in them $[12,13]$.

The soil seepage of a certain site is regulated by precipitation input, evapotranspiration loss, soil water storage change, and surface runoff; the last two items are mostly ignored in long-term studies [1,7]. In alpine humid meadows, evapotranspiration was found to be determined by the availability of radiation energy and to generally recycle almost all precipitation inputs back to the atmosphere [14]. Consequently, shallow soil seepage should be closely related to rainfall (frequency and amount) and soil hydraulic conductivity (which is extremely low in a frozen soil layer) in the short term (daily or monthly) $[5,15]$. Meanwhile, it was found that shallow soil seepage events mainly occurred during the non-frozen periods, with a peak in June [11] or July [10]. However, the degree to which the soil seepage probability and amount are dependent amongst environmental controls is highly constrained. Field soil seepage observations are critical for addressing these issues and could help to deepen our mechanistic understanding of the water cycles in alpine meadows.

Piedmont summer pastures are generally common rangelands and are located at the foot of the mountains, where the soil depth is less than $40 \mathrm{~cm}$ [4]. More importantly, they have been severely degraded because of the tragedy of the commons (individuals neglect the well-being of society in pursuit of personal gain, which leads to over-consumption and ultimately the depletion of common resources), which can substantially affect ecohydrological processes and water budgets [16]. In this study, we used a micro-lysimeter to quantify the seasonal pattern of shallow soil seepage (probability and amount) and the potential environmental controls in a piedmont summer pasture of alpine meadow on the Northeastern Qinghai-Tibetan Plateau. Since a higher precipitation and shallower soil layer were found in summer pastures in comparison to winter pastures [10,11], we hypothesized that soil seepage in the higher-altitude summer pasture would be precipitation-dependent.

\section{Material and Methods}

\subsection{Site Description}

Our experiment was conducted in a piedmont summer pasture of alpine meadow $\left(37^{\circ} 41^{\prime} \mathrm{N}, 101^{\circ} 21^{\prime} \mathrm{E}, 3550 \mathrm{~m}\right.$ a.s.l., Figure $\left.1 \mathrm{a}\right)$. The study site is located $10 \mathrm{~km}$ northeast away from the Haibei National Field Research Station for Alpine Grasslands (hereafter Haibei Station, $37^{\circ} 37^{\prime} \mathrm{N}, 101^{\circ} 19^{\prime} \mathrm{E}, 3200 \mathrm{~m}$ ), which lies on the Northeastern Qinghai-Tibetan Plateau. The climate is typical plateau continental, where the summer is warmer and wetter and the winter is colder and drier. The soil of the summer pasture is a silt loam and about $20-40 \mathrm{~cm}$ in thickness. The soil bulk density and organic carbon content at depths of $0-10 \mathrm{~cm}, 10-20 \mathrm{~cm}$, and $20-40 \mathrm{~cm}$ were 0.59 and $7.53 \%, 0.75$ and $5.96 \%, 1.26 \mathrm{~g} \cdot \mathrm{cm}^{-3}$, and $4.17 \%$, respectively [17].
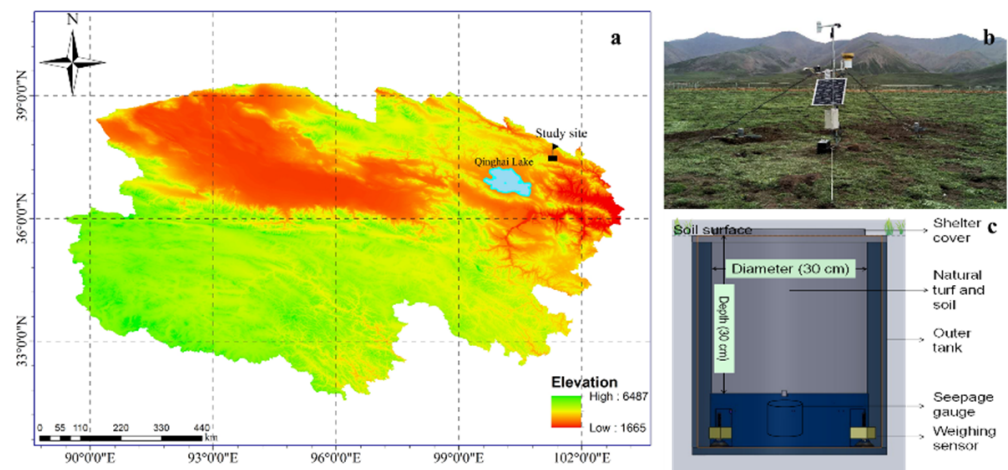

Figure 1. The geographic location of the study site (a), a picture of the experiment in the piedmont summer pasture (b), and a design sketch of a micro-lysimeter (c). 
The vegetation in the piedmont summer pasture is classified as alpine forb meadow. The dominant plants consist of Carex moorcrofti, Leontopodium nanum, Poa pratensis, Saussurea Katochaete, Kobresis humilis, Elymus nutans, and Stipa aliena. The aboveground and topsoil belowground biomass in August were about $190 \mathrm{~g} \cdot \mathrm{m}^{-2}$ and $1040 \mathrm{~g} \cdot \mathrm{m}^{-2}$, respectively [17]. The summer pastures had experienced a heavy grazing intensity $\left(10 \mathrm{sheep} \cdot \mathrm{hm}^{-2}\right)$ and has been seriously degraded (Figure 1b).

\subsection{Micro-Lysimeter and Environmental Variables}

The cylindrical micro-lysimeter we used was $30 \mathrm{~cm}$ in height and $30 \mathrm{~cm}$ in diameter and made of PVC material (Figure 1c). The depth of the lysimeter could cover $95 \%$ of the belowground biomass. The out tanker was installed vertically into the soil, and the top was horizontal to the soil surface. A weighting sensor (5 g precision, corresponding to $0.071 \mathrm{~mm})$ and a tipping bucket rain gauge $(0.003 \mathrm{~mm}$ precision) were installed at the bottom of the out tanker, and they were used to monitor the weight of the inner tanker and soil seepage, respectively. The inner tanker was filled with a block of natural turf and soil of the same size and shape as the drum. The inner tanker filled with soil weighed about $30.0 \mathrm{~kg}$ in total. The infiltrated seepage was automatically pumped out by a micro-pump. The data for the tanker weight and soil seepage were stored using a CR800 datalogger (Campbell, USA) at 30-minute intervals.

Radiation (including incoming/outgoing long-wave radiation, and incoming/outgoing short-wave radiation) was measured with four radiometers (CNR4, Kipp \& Zonen, Netherlands) at a $1.5 \mathrm{~m}$ height. Air temperature and relative humidity were monitored by a temperature and humidity probe (HMP155A-L, Vaisala, Helsinki, Finland) at a $1.5 \mathrm{~m}$ height. Wind speed, wind direction, and precipitation were sampled at a height of $2.2 \mathrm{~m}$ by a cup anemometer, a dogvane (05103, RM Young, USA), and a rain gauge (52203, RM Young, Traverse City, MI, USA), respectively. The daily rainfall frequency (Rain-fre) and maximum rainfall amount (Rain-max) were simply estimated using the cumulative counts and the maximal value of half-hour precipitation throughout the entire day, respectively. The $5 \mathrm{~cm}$ soil temperature and volumetric soil water content were measured synthetically using coaxial impedance dielectric reflectometry (Hydra probe II, Stevens, Portland, OR, USA). Half-hour values of meteorological data were recorded using the other CR800 data logger. The observation system consisting of the micro-lysimeter and the auxiliary meteorological factors has been in use since late May 2018.

\subsection{Statistical Analysis}

The one-year round daily data from July 2018 to June 2019 were analyzed in order to quantify the seasonal pattern of the shallow soil seepage. During the period from April to October when soil seepage occurred, we first defined a daily seepage amount above $0 \mathrm{~mm}$ or equaling $0 \mathrm{~mm}$ as a " 1 " event (soil seepage) or a " 0 " event (non-soil seepage), respectively. The sample volume was 198, with 43 daily soil seepage occurring. Therefore, the dataset of the daily shallow soil seepage probability was not balanced and was analyzed using a boosted regression trees model (BRT). BRT is a machine-learning algorithm and so does not depend on theoretical or empirical assumptions. It can tolerate colinearities and non-linearities for environmental variables, regardless of how the variables are distributed or whether they are independent or not, and it has been widely used in recent relevant studies $[18,19]$. After several tests, the five key parameters in BRT, including tree complexity (the number of terminal nodes of each tree), learning rate (shrinkage parameter, determining the contribution of each tree to the growing model), bag.fraction (the proportion of observations used in selecting variables), n.fold (number of folds crossvalidation), and family (the nature of error structure) were set at $5,0.001,0.90,10$, and "bernoulli", respectively. The main environmental controls included air temperature, solar radiation, rainfall amount, rainfall frequency, rainfall maximum, and volumetric soil water content. The month stage (month: April, May, June, July, August, September, and October) was also used in the models as a categorical variable to explore the potential effect of time. 
The relative contribution to the daily soil seepage probability was based on the number of times one variable was selected for splitting, weighted by the squared improvement of the model as a result of each split, and averaged over all trees. The relative contribution of each variable was scaled so that the sum added up to 100, with higher numbers indicating stronger influence [18].

Secondly, we took the hysteresis effect into consideration, collected the daily soil seepage above $0 \mathrm{~mm}$, and created a 43-row and 26-column matrix with the daily soil seepage amount, soil water content, rainfall amount, rainfall frequency, rainfall maximum, and solar radiation from 4-day, 3-day, 2-day, 1-day, and 0-day before the seepage events. Due to the small size of the data sample $(n=43)$, the forward stepwise linear regression of the whole dataset was performed in order to explore the most important environmental controls on the daily amount of shallow soil seepage. BRT was implemented through the "Dismo" package [18] in R 4.0.2. The leave-one-out cross-validation was also conducted in order to evaluate the performance of the linear model on the daily seepage amount dataset through the "train" function of the "caret" package in R 4.0.2. The stepwise linear regression and other conventional statistical analyses were conducted in SYSTAT 13.0 (Systat Software Inc., Palo Alto, CA, USA), and all the figures were plotted in OriginPro 2016 (OriginLab Cor., Northampton, MA, USA).

\section{Results}

\subsection{Seasonal Pattern of Environmental Variables}

The seasonal variations of climate variables and soil seepage are shown in Figure 2. The air temperature and precipitation averaged $-0.53{ }^{\circ} \mathrm{C}$ and $550.6 \mathrm{~mm}$ during the study period, respectively. The warmest and coldest monthly air temperatures were $9.1^{\circ} \mathrm{C}$ in August and $-12.2{ }^{\circ} \mathrm{C}$ in January, respectively (Figure 2a). The rainfall during the vegetation growing season from June to September was $420.0 \mathrm{~mm}$. The solar radiation averaged $197.7 \mathrm{~W} \mathrm{~m}^{-2}$ and the maximum monthly value was $258.4 \mathrm{~W} \mathrm{~m}^{-2}$ in May (Figure 2b). The monthly $5 \mathrm{~cm}$ volumetric soil water content was about $0.36 \pm 0.03 \mathrm{~cm}^{3} \mathrm{~cm}^{-3}$ (mean \pm S.D., the same below) in the growing season. Although the soil water content increased when high-intensity rainfall occurred (Figure 2c), no significant correlation between the monthly soil water content and monthly rainfall was found $\left(R^{2}=0.04, p=0.30\right)$. The daily half-hour rainfall frequency averaged $5.3 \pm 1.0$ in the growing season. The maximum amount of halfhour rainfall was $10.4 \mathrm{~mm}$, which occurred on August 3, 2018. Linear regression analysis showed that the daily rainfall amount was jointly controlled by the rainfall frequency and rainfall maximum with a similar standardized coefficient ( 0.53 vs. 0.49 ).
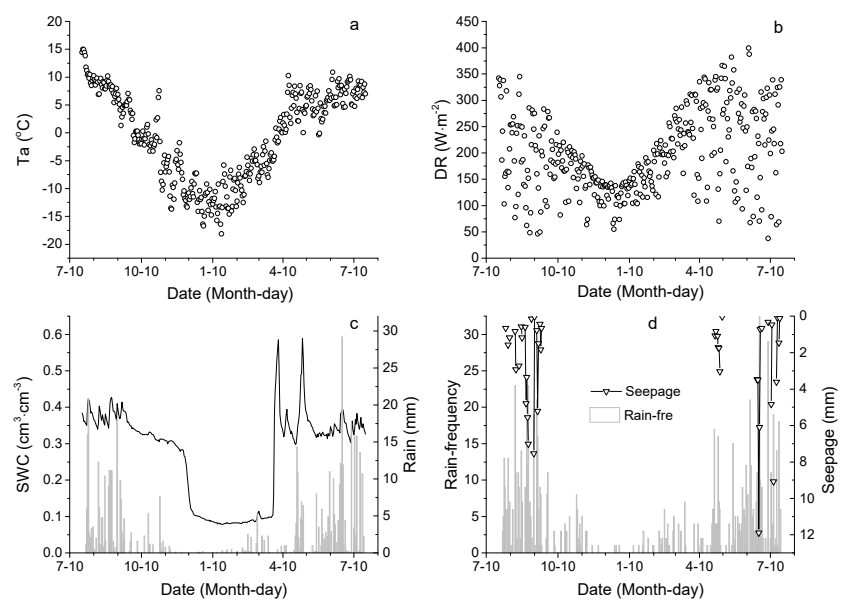

Figure 2. Seasonal variations in daily air temperature (Ta, a), solar direct radiation (DR, b), volumetric topsoil water content (SWC) and rainfall (Rain, c), rainfall frequency (Rain-fre), and shallow soil seepage (Seepage, $\mathbf{d}$ ) in the summer pasture of alpine meadow. 


\subsection{The Probability of Shallow Soil Seepage}

All the shallow soil seepage events occurred from late April to late September (Figure 2d). The mean total deviance and residual deviance of the BRT models on the daily soil seepage probability were 1.05 and 0.58 , respectively, which showed that the model performance was reasonable $\left(R^{2}=0.45\right)$ and comparable with the explanatory power of the traditional binary logistic regression model $\left(R^{2}=0.50\right.$, Table S1). Meanwhile, the 10-fold cross-validation area under the curve (AUC) score was 0.92 (Figure S1). The rainfall frequency, soil water content, and air temperature were the most important environmental controls and completely explained $68 \%$ of the variation in the shallow soil seepage probability (Figure 3). The rainfall frequency and soil water content exerted a positive influence, while air temperature negatively affected the soil seepage probability (Figure S2). It was notable that the soil seepage probability was not related to the month stage, which was indicated by the small contribution $(<5 \%)$ of the month variable to the variability (Figure 3).

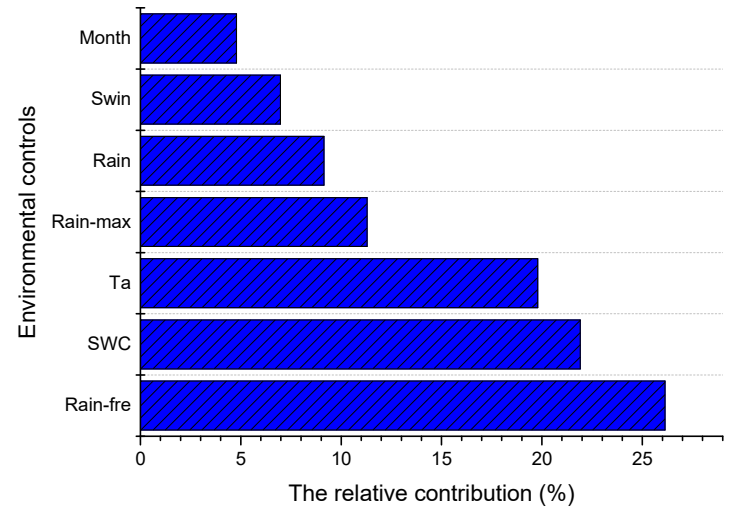

Figure 3. The relative contribution of the main environmental controls to the variability in the daily shallow soil seepage probability (abbreviations: Month is categorical variable for the month period of soil seepage events, Swin is solar radiation, Rain is the rainfall amount, Rain-max is the maximum half-hour rainfall amount, Ta is the air temperature, SWC is the soil water content, and Rain-fre is the rainfall frequency).

\subsection{Seasonal Variations of Soil Seepage and Environmental Controls}

The accumulative shallow soil seepage was $106.8 \mathrm{~mm}$. The maximum monthly soil seepage was $30.7 \mathrm{~mm}$ in September, which was followed by $26.3 \mathrm{~mm}$ in June, $20.4 \mathrm{~mm}$ in August, and $20.0 \mathrm{~mm}$ in July. The minimal monthly soil seepage was $1.0 \mathrm{~mm}$ in April and $8.4 \mathrm{~mm}$ in May (Figure 4c). The soil seepage in the vegetation growing season accounted for $91 \%$ of the total amount of soil seepage. It was interesting that there was little difference $(p=0.91, \mathrm{~N}=5)$ in monthly soil seepage between the daytime $(52.8 \mathrm{~mm})$ and nighttime $(54.0 \mathrm{~mm})$, which might be due to a non-significant difference in precipitation $(p=0.41)$ between the two periods. Ignoring surface runoff, the mean monthly rain yield efficiency (seepage/rainfall) was $24 \%$, where the peak was $41 \%$ in September and the others were $19 \pm 3 \%$. The annual precipitation yield efficiency was $19 \%$.

The forward stepwise linear regression showed that the daily soil seepage amount was determined by the daily rainfall and 2-day rainfall frequency, which could jointly explain $69 \%$ of the variation in the daily soil seepage (Table 1). In addition, the BRT of the daily soil seepage also demonstrated that rainfall was the most important determinant, with a relative contribution of $43 \%$ (Figure S3). The daily rainfall amount, more than rainfall frequency, was the most important environmental control for the daily soil seepage, with a slope of $0.33\left(R^{2}=0.58, p<0.001\right.$, Figure 4a; Figure $\left.4 \mathrm{~b}\right)$. The percentiles of the residuals from the linear regression between the daily soil seepage and daily rainfall amount seemed to be more close to normality, and this was also an indicator of the daily rainfall amount for soil seepage amount (Figure S4). The leave-one-out cross-validation (LOOCV) $R^{2}$ and 
root mean square error (RMSE) from the linear relationship between the daily soil seepage amount and the daily rainfall amount were 0.53 and $1.83 \mathrm{~mm}$, respectively. However, they were 0.15 and $2.48 \mathrm{~mm} \mathrm{~d}^{-1}$ from the linear model between the daily soil seepage and the daily rainfall frequency, respectively. The general linear model further revealed that the main effect of the rainfall amount $(p<0.001)$, rather than the rainfall frequency $(p=0.58)$, exerted a significant influence on the daily soil seepage amount. On a monthly scale, the monthly rainfall frequency alone accounted for $68 \%$ of the variation in the monthly soil seepage amount $\left(p=0.03, \mathrm{~N}=6\right.$, Figure $4 \mathrm{~d}$ ). The LOOCV $R^{2}$ and RMSE were 0.51 and $7.33 \mathrm{~mm}$ month $^{-1}$, respectively. The monthly soil seepage amount was significantly related to the monthly rainfall amount, with which it had an asymptotical relationship (Figure 4c). The LOOCV $R^{2}$ and RMSE were 0.32 and $8.71 \mathrm{~mm} \mathrm{month}^{-1}$ (the rainfall was log-transformed according to Figure 4c), respectively. Therefore, shallow soil seepage was jointly determined by the rainfall frequency and the rainfall amount at daily and monthly scales.
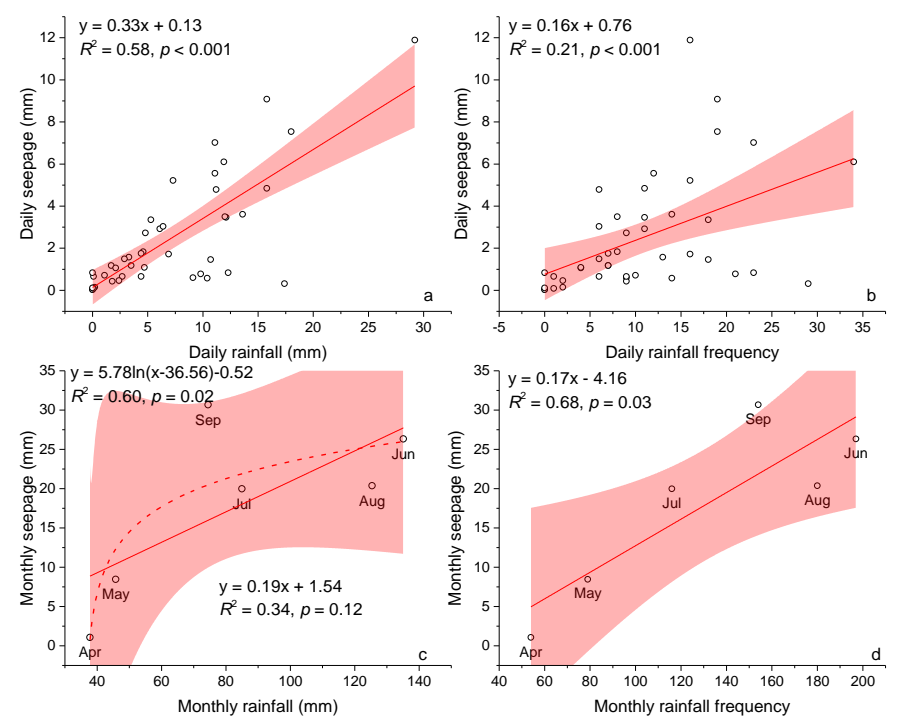

Figure 4. The relationships between soil seepage amount, rainfall amount (a,c), and rainfall frequency (rainfall-fre, b,d) at the daily $(\mathbf{a}, \mathbf{b})$ and monthly $(\mathbf{c}, \mathbf{d})$ scales. The shading areas show the $95 \%$ confidence of the regression line.

Table 1. The forward stepwise linear regressions for the daily soil seepage amount in the summer pasture of alpine meadow (Rain: rainfall amount, Rain-fre-2: the 2-day rainfall frequency before soil seepage).

\begin{tabular}{cccccccc}
\hline Model Size & Variable Selected & Standard Regression Coefficients & $\boldsymbol{p}$ Value & $\boldsymbol{R}^{\mathbf{2}}$ & MSE & Mallow'CP & AIC \\
\hline One variable & Rain & 0.77 & $<0.001$ & 0.59 & 3.06 & 97.07 & 174.70 \\
\multirow{2}{*}{ Two variables } & Rain & 0.88 & $<0.001$ & 0.69 & 2.28 & 62.12 & 163.31 \\
& Rain-fre-2 & 0.35 & $<0.001$ & & & \\
\hline
\end{tabular}

\section{Discussion}

\subsection{The Probability of Soil Seepage Events}

A soil seepage event is a function of rainfall density, terrain slope, and soil infiltrability [7]. The performance of the BRT model was good (Figure S1) and clearly revealed that rainfall frequency played a substantial role in the probability of occurrence of daily shallow soil seepage events (Figure 3, Table S1), which agreed well with the similar results of field experiments $[10,11]$. This could be ascribed to the following two aspects. Firstly, greater soil porosity and higher soil water content would favor soil seepage events. The soil porosity percentage in the $0-40 \mathrm{~cm}$ layer averaged $63.6 \%$, while it averaged $70 \%$ more in the 0-20 cm soil layer [17]. The mean actual topsoil water content was $0.36 \mathrm{~cm}^{3} \cdot \mathrm{cm}^{-3}$ during the growth season (Figure 2c), which was close to the topsoil capillary water ca- 
pacity $\left(0.51 \mathrm{~cm}^{3} \cdot \mathrm{cm}^{-3}[17]\right)$. Therefore, the relatively light-intensity and high-frequency rainfall could favor the occurrence of soil seepage in our piedmont pasture site. Meanwhile, the half-hour rainfall intensity concentrated $0.1-0.5 \mathrm{~mm}$, and their accumulative relative frequency was $54 \%$. Secondly, evapotranspiration losses were energy-limited in this alpine humid site [14]. Although the annual solar radiation was $198.1 \mathrm{~W} \cdot \mathrm{m}^{-2}$, the annual net radiation averaged $61.6 \mathrm{~W} \cdot \mathrm{m}^{-2}$, which was comparable with the value for low-elevation sites [20]. Therefore, the evapotranspiration loss should be relatively low and soil water could not be consumed too much, which would constrain soil seepage substantially (Figure 3). This was partially confirmed by the non-significant difference in soil seepage between the daytime and the nighttime, given that evapotranspiration was much stronger in the daytime [14]. In addition, if the rainfall frequency was excluded in the BRT and logistic model, the rainfall amount became the most important variable in terms of the soil seepage probability (Figure S5; Table S1). Overall, together with the higher soil water content and lower evapotranspiration loss, rainfall exerted a substantial influence on the probability of soil seepage in the piedmont summer pasture of alpine meadow.

\subsection{The Temporal Patterns of Soil Seepage Amount}

Due to the extremely lower hydraulic conductivity and impedance effect of frozen soil [15], soil seepage occurred during the non-frozen period, which agreed well with our knowledge of other similar alpine experiments $[10,11]$. The seasonal pattern of the first peak of $30.7 \mathrm{~mm}$ in September and the second peak of $26.3 \mathrm{~mm}$ in June (Figure 3) coincided with the autumn flooding [16] and spring river discharge [21] of the plateau. The September peak in the summer pasture is clearly different from that seen in June [10] or July [11] in the adjacent winter meadows; such a difference highlighted the spatial heterogeneity of the soil seepage. Detailed works should be carried out.

The rainfall amount and frequency exerted a significant influence on soil seepage in the short term (Figure 4; Table 1). These findings showed that consecutive light rainfall affected the soil seepage amount. This can mainly be attributed to the fact the strong rainfall would stimulate surface runoff more than soil seepage [22]. Furthermore, coarse-textured and high-porosity soils with a high hydraulic conductivity would favor rainfall infiltration in our sites $[5,15]$. Meanwhile, a greater rainfall frequency indicated that there would be more cloudy days and consequent lower net radiations, which could save water from being lost due to evapotranspiration [14]. Together, rainfall, including its amount and frequency, were found to regulate the shallow soil seepage in the piedmont alpine meadow. However, it should be noted that our experiments excluded the effect of lateral soil water flow from meltwater [23], which could reduce the source of water input and then led to the underestimation of soil seepage. Future studies are needed in order to quantify these belowground hydrological processes, together with the grassland degradation and the resultant surface heterogeneity [12].

\section{Conclusions}

All shallow soil seepage events occurred during the non-frozen period from April to September in a piedmont summer pasture of alpine meadow. The daily half-hour rainfall frequency and soil water content were able to determine the probability of daily soil seepage. The daily soil seepage amount was found to be closely related to the daily rainfall amount. The monthly soil seepage peaked in September, followed by June, July, August, and May, which were significantly regulated by the monthly rainfall amounts. The annual soil seepage amount was equivalent to about $1 / 5$ of the annual precipitation. Our results revealed that rainfall, including its frequency and amount, played a dominant role in the seasonal variation in the shallow soil seepage. 
Supplementary Materials: The following are available online at https: / www.mdpi.com/article/ 10.3390/w13202815/s1, Figure S1: The receiver operating characteristic curve (a), Precision/recall (b), Sensitivity/specificity (c) and Lift charts (d) from the boosted regression trees results. The plot was created by the "ROCR" package (Sing T, Sander O, Beerenwinkel N, Lengauer T. ROCR: visualizing classifier performance in R. Bioinformatics 2005, 21(20): 3940-3941) in R 4.0.2; Figure S2: The fitted daily soil seepage probability in relation to each of the predictors used in the model (Month is categorical variable for the month period of soil seepage events, Rain-fre is daily rainfall frequency, Rain-max is the maximum half-hour rainfall amount, Ta is air temperature, Swin is solar radiation, Rain is rainfall amount, and SWC is soil water content); Figure S3: The relative contribution on daily soil seepage from boosted regression trees model (mean total deviance $=7.11$, mean residual deviance $=0.35$. Abbreviations: Rain: rainfall amount; Rain-fre: rainfall frequency; SWC: soil water content; Swin: solar radiation; the suffix number -4, -3,-2,-1 is the 4-day, 3-day, 2-day, and 1-day before seepage events (i.e., Swin-4 is solar radiation of four days before soil seepage event)); Figure S4: The percentiles of residual from linear $(a, b$ and $d)$ and logarithmic regression analysis on daily seepage ( $a$ and $b$ ) and monthly ( $c$ and $d$ ) seepage amount; Figure S5: The relative contribution of main environmental controls (rainfall frequency was excluded) on daily soil seepage probability from boosted regression trees model (mean total deviance $=1.05$, mean residual deviance $=0.51$. abbreviations: Month is categorical variable for the month period of soil seepage events, Swin is solar radiation, Rain is the rainfall amount, Rain-max is the maximum half-hour rainfall amount, Ta is the air temperature, SWC is the soil water content); Table S1: The forward method (Likelihood Ratio) binary Logistic regressions of daily soil seepage events in the summer pasture of alpine meadow (Rain-fre: rainfall frequency; SWC: soil water content; Rain: rainfall amount).

Author Contributions: F.Z., H.L. and Y.Y. carried out all analyses. X.G., L.L., Y.L. (Yikang Li) wrote the manuscript; Y.L. (Yingnian Li), G.C. and H.Z. acquired the financial support for the project leading to this publication F.Z. conceived the manuscript. All authors collaborated in the interpretation of the results and the writing of the paper. All authors have read and agreed to the published version of the manuscript.

Funding: This work was funded by the National Natural Science Foundation of China (41730752, 41877547), the Chinese Academy of Sciences-People's Government of Qinghai Province Joint Grant on Sanjiangyuan National Park Research (YHZX-2020-07), and Qinghai Innovation Platform Construction Project (2021-ZJ-Y01).

Institutional Review Board Statement: Not applicable.

Informed Consent Statement: Not applicable.

Data Availability Statement: The data presented in this study are available on request from the corresponding author.

Acknowledgments: We sincerely thank the two anonymous referees for their constructive comments on the earlier manuscript.

Conflicts of Interest: The authors declare no conflict of interest.

\section{References}

1. Chapin, F.S.; Matson, P.A.; Mooney, H.A. Principles of Terrestrial Ecosystem Ecology, 2nd ed.; Springer: New York, NY, USA, 2011.

2. D'Odorico, P.; Laio, F.; Porporato, A.; Ridolfi, L.; Rinaldo, A.; Rodriguez-Iturbe, I. Ecohydrology of terrestrial ecosystems. Bioscience 2010, 60, 898-907. [CrossRef]

3. Gao, J.; Yao, T.; Masson-Delmotte, V.; Steen-Larsen, H.C.; Wang, W. Collapsing glaciers threaten Asia's water supplies. Nature 2019, 565, 19-21. [CrossRef] [PubMed]

4. Zheng, D.; Zhang, Q.S.; Wu, S.H. Mountain Geoecology and Sustainable Development of the Tibetan Plateau; Kluwer Academic: Dordercht, The Netherlands, 2000.

5. Zhang, F.; Li, H.; Li, Y.; Guo, X.; Dai, L.; Lin, L.; Cao, G.; Li, Y.; Zhou, H. Strong seasonal connectivity between shallow groundwater and soil frost in a humid alpine meadow, northeastern Qinghai-Tibetan Plateau. J. Hydrol. 2019, 574, 926-935. [CrossRef]

6. Bayard, D.; Stähli, M.; Parriaux, A.; Flühler, H. The influence of seasonally frozen soil on the snowmelt runoff at two Alpine sites in southern Switzerland. J. Hydrol. 2005, 309, 66-84. [CrossRef] 
7. Wilcox, B.P.; Le Maitre, D.; Jobbagy, E.; Wang, L.; Breshears, D.D. Ecohydrology: Processes and Implications for Rangelands. In Rangeland Systems: Processes, Management and Challenges; Briske, D.D., Ed.; Springer International Publishing: Cham, Switzerland, 2017; pp. 85-129.

8. Ge, S.; Wu, Q.B.; Lu, N.; Jiang, G.L.; Ball, L. Groundwater in the Tibet Plateau, western China. Geophys. Res. Lett. 2008 , 35 , L18403. [CrossRef]

9. Ge, S.; McKenzie, J.; Voss, C.; Wu, Q. Exchange of groundwater and surface-water mediated by permafrost response to seasonal and long term air temperature variation. Geophys. Res. Lett. 2011, 38, L14402. [CrossRef]

10. Yang, Y.; Li, H.; Zhang, L.; Zhu, J.; He, H.; Wei, Y.; Li, Y. Characteristics of soil water percolation and dissolved organic carbon leaching and their response to long-term fencing in an alpine meadow on the Tibetan Plateau. Environ. Earth Sci. 2016, 75, 1471. [CrossRef]

11. Dai, L.; Guo, X.; Zhang, F.; Du, Y.; Ke, X.; Li, Y.; Cao, G.; Li, Q.; Lin, L.; Shu, K.; et al. Seasonal dynamics and controls of deep soil water infiltration in the seasonally-frozen region of the Qinghai-Tibet plateau. J. Hydrol. 2019, 571, 740-748. [CrossRef]

12. Levia, D.F.; Creed, I.F.; Hannah, D.M.; Nanko, K.; Boyer, E.W.; Carlyle-Moses, D.E.; van de Giesen, N.; Grasso, D.; Guswa, A.J.; Hudson, J.E.; et al. Homogenization of the terrestrial water cycle. Nat. Geosci. 2020, 13, 656-658. [CrossRef]

13. Ireson, A.M.; Kamp, G.V.D.; Ferguson, G.; Nachshon, U.; Wheater, H.S. Hydrogeological processes in seasonally frozen northern latitudes: Understanding, gaps and challenges. Hydrogeol. J. 2013, 21, 53-66. [CrossRef]

14. Zhang, F.; Li, H.; Wang, W.; Li, Y.; Lin, L.; Guo, X.; Du, Y.; Li, Q.; Yang, Y.; Cao, G.; et al. Net radiation rather than moisture supply governs the seasonal variations of evapotranspiration over an alpine meadow on the northeastern Qinghai-Tibetan Plateau. Ecohydrology 2018, 11, e1925. [CrossRef]

15. Hinzman, L.D.; Kane, D.L.; Gieck, R.E.; Everett, K.R. Hydrologic and thermal properties of the active layer in the Alaskan Arctic. Cold Reg. Sci. Technol. 1991, 19, 95-110. [CrossRef]

16. Wang, G.X.; Li, Y.S.; Hu, H.C.; Wang, Y.B. Synergistic effect of vegetation and air temperature changes on soil water content in alpine frost meadow soil in the permafrost region of Qinghai-Tibet. Hydrol. Process. 2008, 22, 3310-3320. [CrossRef]

17. Wu, Q.; Mao, S.; Liu, X.; Li, H.; Zhang, F.; Li, Y. Analysis of the soil water-holding capacity in alpine forb meadow under grazing gradient and relevant influence factors. J. Glaciol. Geocryol. 2014, 36, 590-598, (In Chinese with English abstract).

18. Elith, J.; Leathwick, J.R.; Hastie, T. A working guide to boosted regression trees. J. Anim. Ecol. 2008, 77, 802-813. [CrossRef] [PubMed]

19. Li, H.; Wang, C.; Zhang, F.; He, Y.; Shi, P.; Guo, X.; Wang, J.; Zhang, L.; Li, Y.; Cao, G.; et al. Atmospheric water vapor and soil moisture jointly determine the spatiotemporal variations of $\mathrm{CO}_{2}$ fluxes and evapotranspiration across the Qinghai-Tibetan Plateau grasslands. Sci. Total Environ. 2021, 791, 148379. [CrossRef] [PubMed]

20. Zhang, X.; Gu, S.; Zhao, X.; Cui, X.; Zhao, L.; Xu, S.; Du, M.; Jiang, S.; Gao, Y.; Ma, C.; et al. Radiation partitioning and its relation to environmental factors above a meadow ecosystem on the Qinghai-Tibetan Plateau. J. Geophys. Res. Atmos. 2010, 115, D10106. [CrossRef]

21. Cao, J.; Qin, D.; Kang, E.; Li, Y. River discharge changes in the Qinghai-Tibet Plateau. Chin. Sci. Bull. 2006, 51, 594-600. [CrossRef]

22. Wang, G.; Hu, H.; Li, T. The influence of freeze-thaw cycles of active soil layer on surface runoff in a permafrost watershed. J. Hydrol. 2009, 375, 438-449. [CrossRef]

23. Jiang, X.; Zhu, X.; Yuan, Z.; Li, X.G.; Liu, W.; Zakari, S. Lateral flow between bald and vegetation patches induces the degradation of alpine meadow in Qinghai-Tibetan Plateau. Sci. Total Environ. 2021, 751, 142338. [CrossRef] [PubMed] 